\title{
ANTIFUNGAL ACTIVITY OF EXTRACT AND FRACTION OF AURICULARIA AURICULAR ON CANDIDA ALBICANS, MICROSPORUM GYPSEUM, AND ASPERGILLUS FLAVUS
}

\author{
IKA KURNIA SUKMAWATI*, ARI YUNIARTO, DIAH RAKHMAWATI
}

Department of Pharmacy Bandung School of Pharmacy, Jalan Sukarno Hatta No 754, Bandung, Indonesia. Email: Ika.kurnia@stfb.ac.id Received: 05 December 2017, Revised: 8 February 2018 Accepted: 14 February 2018

ABSTRACT

Objective: Indonesia with high humidity and rainfall strongly supports the growth of fungi. The incidence of fungal infections has increased dramatically over the past three decades. Several factors including microbiological resistance led to the failure of antifungal therapy. This research was to evaluate the antifungal activity of extract and fraction of Auricularia auricula against the test fungus.

Methods: Antifungal activity was performed by microdilution method using extract and n-hexane fraction, ethyl acetate fraction, methanol, and water fraction of A. auricula. MIC was determined by observing the turbidity compared with the control solution. Minimum fungicidal concentration (MFC) was determined by the presence of fungi colonies growth on medium after incubation for $24 \mathrm{~h}$.

Results: The fractions of $A$. auricular have antifungal activity against Candida albicans, with MIC $512 \mu \mathrm{g} / \mathrm{ml}$ and MFC $512 \mu \mathrm{g} / \mathrm{ml}$; Microsporum gypseum with MIC $256 \mu \mathrm{g} / \mathrm{ml}$ in the extract; MIC $512 \mu \mathrm{g} / \mathrm{ml}$ and MFC $512 \mu \mathrm{g} / \mathrm{ml}$ of ethyl acetate fraction; MIC $256 \mu \mathrm{g} / \mathrm{ml}$ and MFC $512 \mu \mathrm{g} / \mathrm{ml}$ in n-hexane fraction; and Aspergillus flavus with MIC $2048 \mu \mathrm{g} / \mathrm{ml}$ and MFC $2048 \mu \mathrm{g} / \mathrm{ml}$ in the extract and ethyl acetate fraction. The most potent activity on C. albicans was exhibited by ethyl acetate fraction with MIC and MFC $512 \mu \mathrm{g} / \mathrm{ml}$. Scanning electron microscopy showed changes in the structure of fungi cells after contact with the test solution.

Conclusion: The best antifungal activity of $A$. auricula was ethyl acetate fraction against $C$. albicans.

Keywords: Antifungal activity, Auricularia auricula, Candida albicans, Microsporum gypseum and Aspergillus flavus

(C) 2018 The Authors. Published by Innovare Academic Sciences Pvt Ltd. This is an open access article under the CC BY license (http://creativecommons. org/licenses/by/4. 0/) DOI: http://dx.doi.org/10.22159/ajpcr.2018.v11s1.26591

\section{INTRODUCTION}

Infectious diseases are the highest contributor to morbidity and mortality rates in developing countries including Indonesia [1]. Indonesia with high humidity and rainfall strongly supports the growth of fungi. The incidence of fungal infections has increased dramatically over the past three decades. Several factors including microbiological resistance led to the failure of antifungal therapy [2].

Indonesia Health Profile 2010 which shows that skin diseases and subcutaneous tissue are ranked third of the top 10 diseases in outpatients in hospitals throughout Indonesia based on the number of visits that are 192,414 visits and 122,076 visits are new cases [3].

An alternative antifungal therapy is needed, one of them from $A$. auricula. A. auricula is a food ingredient that contains nutrients and minerals such as protein, fat, carbohydrates, fiber, ash, and vitamins such as thiamin $0.015 \mathrm{mg}$; riboflavin $0.844 \mathrm{mg}$; niacin $6.267 \mathrm{mg}$; pantothenic acid $0.481 \mathrm{mg}$; Vitamin B6 $0.112 \mathrm{mg}$; and $38 \mathrm{mcg}$ of folate. In addition, this plant has been used for traditional treatment as an antidote in the body, prevent cancer, cure heart disease and stroke, and blood circulation [4].

According to the journal antimicrobial activity of some local mushrooms on pathogenic isolates, it is mentioned that ethanol extract from mushroom $A$. auricula has antifungal activity against Candida albicans with the inhibition zone of $4.89 \mathrm{~mm}$ and MIC and MBC value of $50 \mathrm{mg}$ [5].

\section{METHODS}

\section{Chemical and reagents}

The main materials used in this study were A. auricula, potato dextrose agar (PDA) MERCK, nystatin, 96\% ethanol solvent, n-hexane, ethyl acetate, methanol, aquades, DMSO solvent MERCK, sodium hydroxide, gelatin, aliquot, Liebermann reagent Bouchardat, Dragendorff's reagent, reagent Mayer, $\mathrm{Mg}$ powders, $\mathrm{H}_{2} \mathrm{SO}_{4}, \mathrm{FeCl}, \mathrm{NaCl}, \mathrm{BaCl}$, and paper discs.

\section{Method}

Collection of test plants, determination, extraction, and fractionation Mushroom A. auricula wet obtained from Caringin Market, Bandung, West Java. Furthermore, the determination was made in the Department of Biology Faculty of Mathematics and Natural Sciences Padjadjaran University. Peak mushroom processing is wet sorting, washing, dry sorting, chopping to become the small part, drying in direct sun heat, and milling to become powder simplicia. The A. auricula that has been treated is extracted by reflux using 96\% ethanol. A total of 100 $\mathrm{g}$ of sample were put into a round bottom flask and $96 \%$ ethanol was added as much as $500 \mathrm{~mL}$. The extract was carried out for $4 \mathrm{~h}$. The liquid ethanol extract obtained was fed to a rotary evaporator and then evaporated until a viscous extract was obtained. The condensed extract was then screened for phytochemical and fractionation.

The ethanol extract was dissolved in a methanol-water mixture (2:8) and placed in a separating funnel, into which an n-hexane solvent was added with a ratio of $1: 1$, then shaken gently until mixed, then sterilized to a proper separating into two phases comprising phase n-hexane and water phase. The n-hexane phase is separated and the water phase is fractionated back up to 3 times. The collected n-hexane phase was concentrated using a rotary evaporating device and a water bath. The water phase is fractionated back using a 1:1 ethyl acetate solvent, this fractionation process is carried out 3 times until the phase of ethyl acetate and water phase, each of which is concentrated by a rotary evaporating device and a water bath. From fractionation obtained a fraction of n-hexane, ethyl acetate, and water [1].

\section{Test fungus}

C. albicans and Microsporum gypseum fungi were obtained from the Laboratory of Microbiology, School of Pharmacy, ITB. The Aspergillus 
flavus fungus was obtained from the Microbiology Laboratory, UNPAD.

\section{Media creation}

PDA of $39 \mathrm{~g}$ dissolved in $1 \mathrm{~L}$ aquades, and potato dextrose broth of 24 $\mathrm{g}$ in $1 \mathrm{~L}$ of aquades and heated to complete dissolved. Before use, all media were sterilized with an autoclave at $121^{\circ} \mathrm{C}$ for $15 \mathrm{~min}$.

\section{Making mushroom suspension}

Microbes were suspended into a liquid medium and incubated 18-24 h at $25^{\circ} \mathrm{C}$. The suspension is shaken and turbidity adjusted to a standard of $0.5 \mathrm{McF}$ turbidity. The turbidity standard of $0.5 \mathrm{McF}$ contains bacteria of $108 \mathrm{CFU} / \mathrm{mL}$, yielding absorbances at $530 \mathrm{~nm}$

(optical density wavelengths should be between 0.08 and 0.10 ). McFarland's half standard is equivalent to $1-5 \times 106$ yeast/mL (density recommended by CLSI for mushroom inoculum stock) [6]

\section{Test antifungal activity}

A $100 \mu \mathrm{L}$ gross domestic product (GDP) is inserted in the microplate in the first column (as a negative control). $5 \mu \mathrm{L}$ mushroom suspension added to $10 \mathrm{~mL}$ of GDP is then stirred with a vortex. A total of 100 $\mu \mathrm{L}$ of the mixture are inserted in the microplate on the second to the $12^{\text {th }}$ column. In the $12^{\text {th }}$ column, $100 \mu \mathrm{L}$ of an antibiotic solution/ extract was added with a certain concentration and homogenized. From the $12^{\text {th }}$ column, taken $100 \mu \mathrm{L}$, then moved the $11^{\text {th }}$ column. Dilution continues until the third column has the smallest concentration. The plates were incubated at $25^{\circ} \mathrm{C}$ for $3 \times 24 \mathrm{~h}$, then observed clear parts (no microbial growth). The smallest concentration in which no visible microbial growth was observed is defined as MIC. A $5 \mu \mathrm{L}$ aliquot of each clear part was removed in a PDA and incubated at $25^{\circ} \mathrm{C}$ for $3 \times 24 \mathrm{~h}$ was then observed. The lowest concentration in which no microbial growth was observed was defined as the minimum fungicidal concentration [7].

\section{Bioautographic test}

The $15 \mathrm{~mL}$ PDA medium mixed with $0.2 \mathrm{~mL}$ of $C$. albicans suspension was poured into a sterile Petri dish and allowed to solidify. After the media solidifies, the eluted thin-layer chromatography (TLC) plate is placed on the surface of the agar medium. After $30 \mathrm{~min}$, the plates were removed and then the medium which had been occupied by TLC plate incubated at $25^{\circ} \mathrm{C}$ for $24 \mathrm{~h}$, observed the constricted zone [8].

\section{Test of antifungal equality}

The equivalent activity of the test substance with comparative antifungals was performed by agar diffusion method. The antifungal used as a comparison is nystatin. Various comparative antifungal concentrations were prepared using a suitable solvent such as those listed in Pharmacopoeia Indonesia IV edition. Based on the measurement of antibiotic inhibitory diameter, a line equation between concentration logarithm and drag diameter is made. The obtained equation is used to see the equality of activity between the test extract and the antibiotic comparison [9].

\section{Scanning electron microscopy (SEM)}

The preparation of SEM testing was initiated by experimental culturing on PDA media incubated at $25^{\circ} \mathrm{C}$ for $24 \mathrm{~h}$. The result of rejuvenation was taken and inserted on Eppendorf tube filled with $\mathrm{NaCl}$, then centrifugation was done for 15 min with speed $3000 \mathrm{rpm}$. Sedimentation of centrifugation result was taken and test substance was added to $8 \mathrm{X}$ KHM concentration for $4 \mathrm{~h}$. After contact with the test substance, then centrifugation was done for 15 min with a speed of $3000 \mathrm{rpm}$ again to separate the sediment and test substances. The precipitate was removed and $10 \%$ formalin was stored in the refrigerator temperature. For testing with SEM device, the formalin solution is removed, the precipitate is placed on the holder specimen and dried on the desiccator for $15 \mathrm{~min}$, then coating with gold for $4 \mathrm{~min}$. Subsequent specimen holder was inserted into chamber specimen and a sample was analyzed by SEM.

\section{RESULTS}

The result of processing showed the dry A. auricula simplicia obtained was $1018.72 \mathrm{~g}$. The extraction result obtained rendemen as much as $2.314 \%$. Phytochemical screening is performed to determine the presence of classes of compounds in a plant, this is done as initial information in knowing any chemical compounds contained in a plant. The results of phytochemical screening showed on A. auricula contain an alkaloid, steroid/triterpenoid, and tannin. Preparation of the fraction is carried out by means of liquid-liquid extraction (ECC) with n-hexane, ethyl acetate, and methanol:water (2:8) solvents. It was found that n-hexane fraction rendement was $22.2 \%$, ethyl acetate fraction was $1.8 \%$, and methanol fraction: $37.6 \%$ water.

\section{Test antifungal activity}

Test of antifungal activity against $C$. albicans, M. gypseum, and A. flavus was done in microdilution with the test substance in the extract of fungus with nystatin as a comparison. The microdilution method is expected to know the value of minimum inhibitory concentration (KHM) and fungicidal minimum (KFM) concentration of the sample to be tested. In testing, the antifungal activity was first made extract and fraction solution with a concentration of $1024 \mu \mathrm{g} / \mathrm{mL}$. The concentration can facilitate the calculation of dilution in the next stages. The solution of extract and fraction will be diluted in liquid medium to concentration of $1 \mu \mathrm{g} / \mathrm{mL}$. Different concentrations will show the strength and number of compounds contained in the solution of extracts and fractions having antifungal activity, at this stage in the search for the smallest concentration that can inhibit the growth of the test fungus with the turbidity indicator of the test media added the test mushroom with the extract and fraction solution which is compared with the positive control of the media plus the test fungus and the negative control of the media only, if the media is cloudy, then it is assumed to be the growth of test fungi and if the clear media such as negative control, hence, assumed the growth of test fungus is inhibited by extract solution and added fraction. The results of antifungal activity test can be seen in Table 1 .

\section{Equality test}

In this test, the equivalence test was carried out between ethyl acetate fraction and nystatin on $C$. albicans fungus. The equivalent test is done by diffusion method that is paper disc method with several series of solution concentration. Selected paper disk method is easy because of its procedure and requires a little volume of solution. The solution of solution concentration is based on the best KHM value of microdilution test. Concentrations made from the ear fungus ethyl acetate fraction are $100,500,1000,5000,10,000$, and $50,000 \mu \mathrm{g} / \mathrm{mL}$. Nystatin as a compound was made with concentrations of $10,25,50,100,250$, and $500 \mu \mathrm{g} / \mathrm{mL}$. From the results of the antifungal equivalence test shows the existence of a clear zone around the disc of paper which means the concentration used has antifungal activity. The equivalence test results of the fungal and ethyl acetate fraction of $C$. albicans can be seen in Tables 2 and 3.

Table 1: Antifungal activity test results

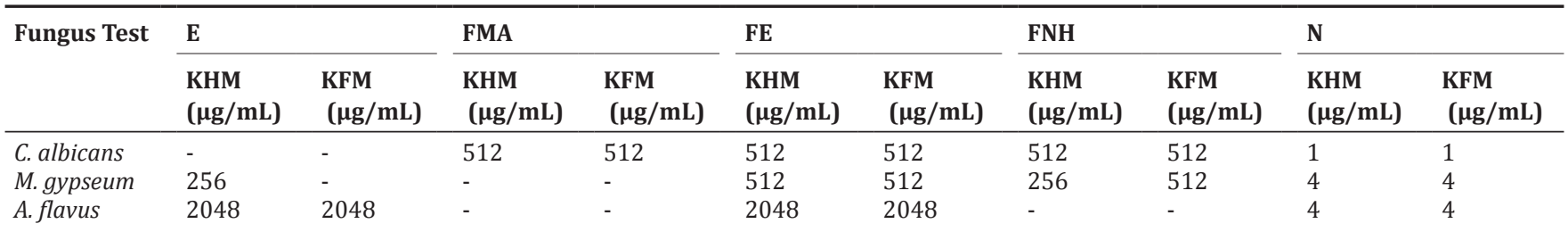

A. flavus: Aspergillus flavus, C. albicans: Candida albicans, M. gypseum: Microsporum gypseum 
From the table of nystatin inhibitory diameters on Candida albicans, a graph of line equation is then made to determine the equivalence value of the ethyl acetate fraction of the fungus Auricularia auricula with nystatin. The graph of the line equation can be seen in Fig. 1.

The value of equality test was obtained by taking one concentration data and the inhibitory diameter of the fungus ethyl acetate fraction. The result of testing of nystatin inhibition diameter, then made calibration curve with drag diameter ( $\mathrm{mm}$ ) on y-axis and logarithm of comparative antifungal concentration the $\mathrm{x}$-axis, so that we can get the equation of a line. The best inhibitory diameter, substituted into the equation $y=b x+a$ as the $y$ value, so that the value of $x$ will be obtained, then the value of $x$ is antilog. The result of inferential antifungal inhibitory diameter was obtained by linear regression equation $y=4.2143 x+2.8333$ and $\mathrm{R}^{2}=0.9845$. Ethyl acetate fungus fraction against $C$. albicans at the concentration of $100 \mu \mathrm{g} / \mathrm{mL}$ yielded a diameter of 7.25 . Selected at a concentration of $100 \mu \mathrm{g} / \mathrm{mL}$ because it produces a resistor diameter that is almost equal to one of the inhibitory diameters of nystatin. The value is then substituted on the equation $y=4.2143 x+2.8333$ as the value of $y$. Obtained value 1.048 and then in antilog and obtained value which is equivalent with comparative that is $11.16 \mu \mathrm{g} / \mathrm{mL}$. The equilibrium count of the ethyl acetate fraction to nystatin was $0.1 \mathrm{mg} / \mathrm{mL}$ of the fungal ethyl acetate fraction equivalent to $0.01116 \mathrm{mg} / \mathrm{mL}$ nystatin.

\section{Bioautographic test}

Bioautographic tests are used to estimate the class of compounds that have activity as an antifungal. Bioautographic tests were performed using contact bioautography method on the solid medium of Potato Dextrosa Agar. Observations were made by looking at inhibitory diameter compared with the previous monitoring results can be seen in Fig. 2.

After incubation, there was a clear zone with Rf values of 0.90 and 0.854 on the medium, then matched with the monitoring results of ethyl acetate fungus fraction on TLC. Bioautographic test results are estimated to a class of active compounds as antifungals are a group of steroids having Rf value of 0.863 .

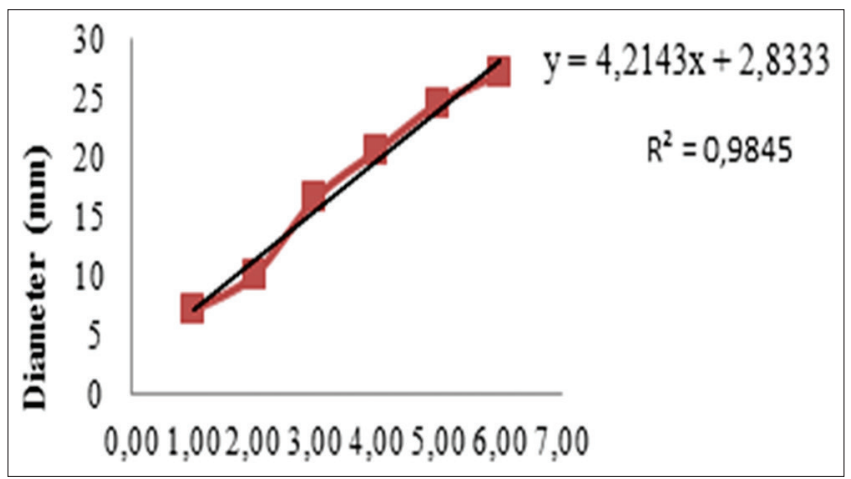

Fig. 1: Graph of nystatin line equations
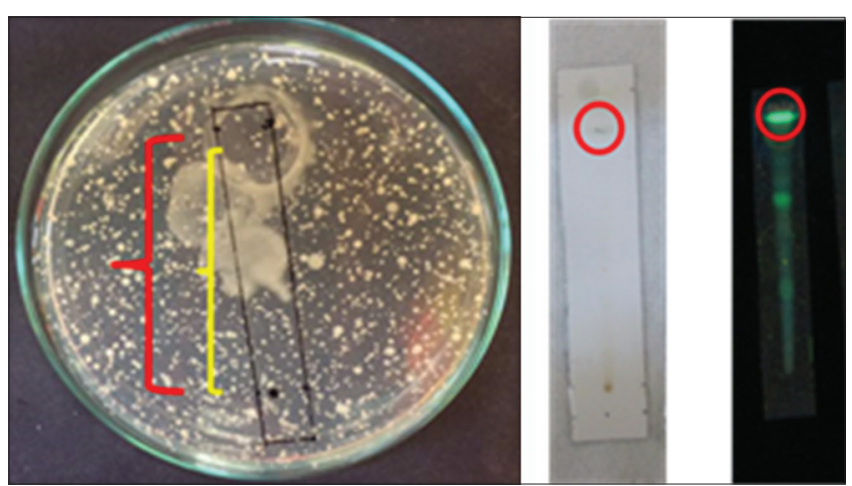

Fig. 2: Bioautographic test results

\section{Test SEM}

Samples tested were $C$. albicans on ethyl acetate fraction, n-hexane fraction, methanol fraction:water, and M. gypseum on extract and n-hexane fraction. This test is based on KHM results from the activity test that has been done. In the SEM test, the test fungus is contacted with an extract/fraction solution of 8 X KHM. Changes in the morphology of the SEM test can be seen in Fig. 3 .

a - Normal Candida albicans cells (controls),

b - C. albicans cells after exposure to ethyl acetate fraction,

c - C. albicans cells after exposure to the n-hexane fraction,

$\mathrm{d}$ - C. albicans cells after exposure to the methanol fraction:water,

e - Normal Microsporum gypseum cell (control),

f - M. gypseum cell after exposure to the extract,

g - M. gypseum cells after exposure to the n-hexane fraction

The results of SEM on C. albicans fungus seen at $\times 20,000$ magnification, cell morphology changes after exposure with ethyl acetate fraction in the form of cell to dent, formed a dimple in the middle of the mushroom cell (Fig. 3b). In fungal cells exposed to the n-hexane fraction, the morphological changes of the cell become dents and there is a bulge on one side of the cell (Fig. 3c). In fungal cells are contacted with the methanol fraction:morphological water in the form of fungal cells becomes shrunken (Fig. 3d). Morphological changes occurring in the M. gypseum fungus seen at $\times 1500$ magnification of fungus cells exposed to extracts become shrunken ( $\mathrm{F}$ image), whereas in the fraction of $\mathrm{n}$-hexane in the form of spots on cells (Fig. 3g).

\section{DISCUSSION}

Determination results showed that the plant that was determined by A. auricular. Extraction is used reflux method because the process is easy, simple, fast, and more effective because of continuous saving so it is more efficient solvent. The use of ethanol solvent because it is more selective, neutral, in higher concentrations can prevent the growth of fungus on the extract. Fractionation is used selected Liquid-liquid extraction (ECC) method because it is simple, easy, and fast. Selection of three types of solvent to attract compounds that are non-polar, semipolar, and polar.

Test of antifungal activity against $C$. albicans, M. gypseum, and A. flavus was done in microdilution with test substance in the extract of fungus with nystatin as the comparison. The microdilution method is expected to know the value of minimum inhibitory concentration (KHM) and fungicidal minimum (KFM) concentration of the sample to be tested.

From the results of antifungal activity test on $C$. albicans fungus, $M$. gypseum, and $A$. flavus, the fraction of water-methanol, ethyl acetate fraction, and n-hexane fungus fraction is active test substances in inhibiting the growth of $C$. albicans fungus. This can be seen from the value of KHM and KFM of $512 \mu \mathrm{g} / \mathrm{mL}$ and $512 \mu \mathrm{g} / \mathrm{mL}$. In the most active M. gypseum fungus inhibited the n-hexane fraction with KHM and KFM values of 256 $\mu \mathrm{g} / \mathrm{mL}$ and $512 \mu \mathrm{g} / \mathrm{mL}$. While in the active A. flavus mushroom inhibits the extract and fraction of ethyl acetate with KHM and KFM value of 2048 $\mu \mathrm{g} / \mathrm{mL}$ and $2048 \mu \mathrm{g} / \mathrm{mL}$. From this antifungal activity test data, one of the best results was chosen for further activity test which included equality test and bioautography. The best activity test data selected were the ethyl acetate fraction in the $C$. albicans test fungus. The reason for this data was chosen because in triploid test KHM and KFM values were always consistent at $512 \mu \mathrm{g} / \mathrm{mL}$ while in M. gypseum and A. flavus fungi only on

Table 2: Diameter of ethyl acetate fraction in C. albicans

\begin{tabular}{ll}
\hline Concentration $(\boldsymbol{\mu g} / \mathbf{m L})$ & $(\mathbf{m m} \pm \mathbf{S D})$ \\
\hline 100 & $7.25 \pm 0.90$ \\
500 & $8.17 \pm 0.29$ \\
1000 & $8.17 \pm 0.29$ \\
5000 & \\
10,000 & $8.50 \pm 2.18$ \\
50,000 & $8.92 \pm 3.32$ \\
\hline
\end{tabular}

C. albicans: Candida albicans, SD: Standard deviation 

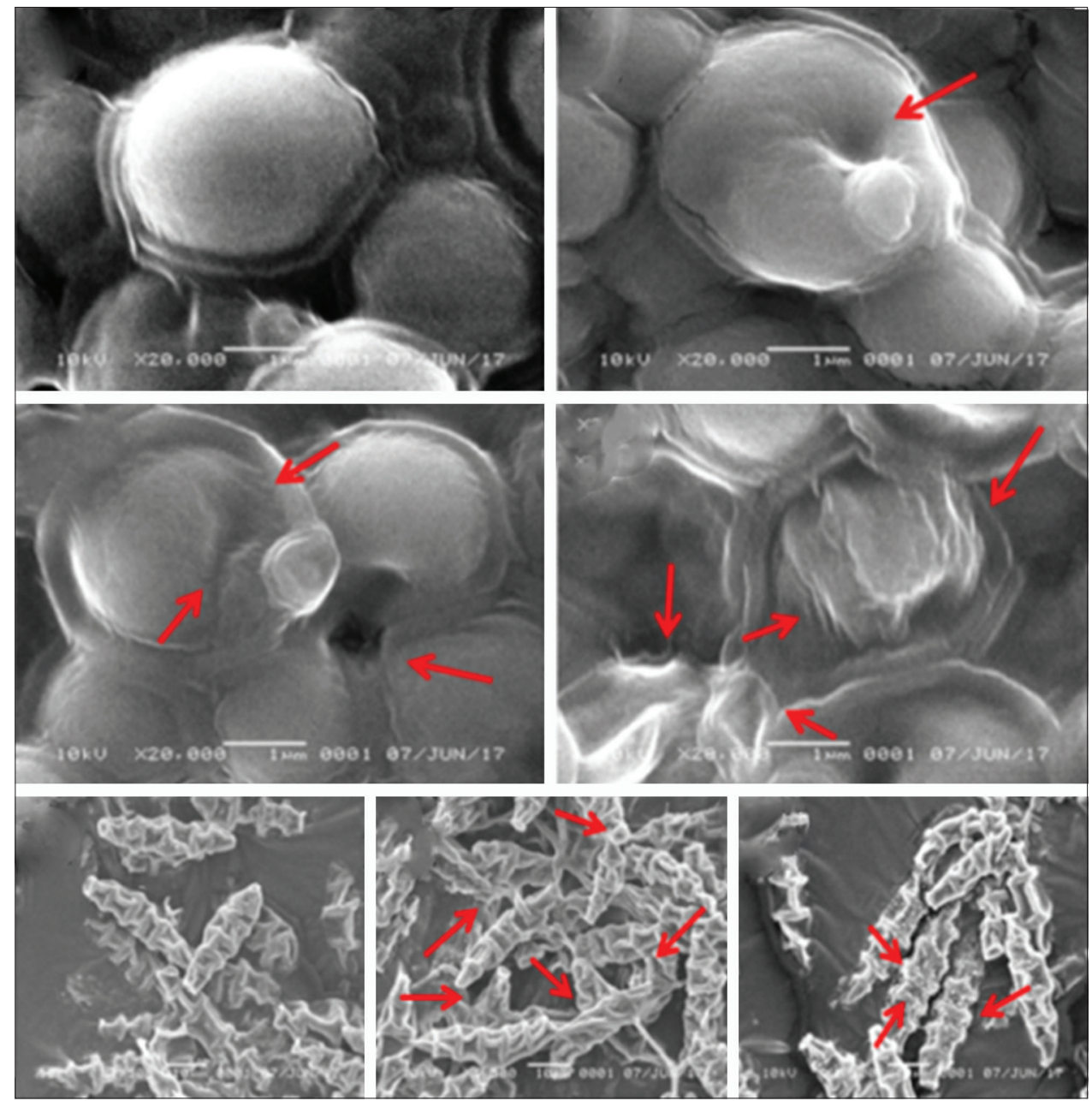

Fig. 3: Scanning electron microscopy test results information. A - Normal Candida albicans cells (controls), B - C. albicans cells after exposure to ethyl acetate fraction, $C$ - C. albicans cells after exposure to the n-hexane fraction, D - C. albicans cells after exposure to the methanol fraction:water, E - Normal Microsporum gypseum cell (control), F - M. gypseum cell after exposure to the extract, G - M. gypseum cells after exposure to the $n$-hexane fraction

Table 3: Diameter of nystatin in C. albicans

\begin{tabular}{lll}
\hline Concentration $(\mu \mathrm{g} / \mathrm{mL})$ & Log concentration $(\mu \mathrm{g} / \mathrm{mL})(\mathrm{x})$ & Inhibitory diameter $(\mathrm{mm} \pm \mathbf{S D}) *(\mathrm{y})$ \\
\hline 10 & 1.00 & $7.0 \pm 0.16$ \\
25 & 1.40 & $10.0 \pm 0.50$ \\
50 & 1.70 & $16.5 \pm 0.44$ \\
100 & 2.00 & $20.5 \pm 0.14$ \\
250 & 2.40 & $24.5 \pm 0.14$ \\
500 & 2.70 & $27.0 \pm 0.38$ \\
\hline
\end{tabular}

C. albicans: Candida albicans, SD: Standard deviation

one column showing the best activity of the triple test.

The equality test is done to determine the equivalence of the best extract/fractions with the comparison drug. The equilibrium count of the ethyl acetate fraction to nystatin was $0.1 \mathrm{mg} / \mathrm{mL}$ of the fungal ethyl acetate fraction equivalent to $0.01116 \mathrm{mg} / \mathrm{mL}$ nystatin.

Bioautographic tests are used to estimate the class of compounds that have activity as an antifungal. Bioautographic tests were performed using contact bioautography method on the solid medium of Potato Dextrosa Agar. Bioautographic test results are estimated to a class of active compounds as antifungals are a group of steroids having Rf value of 0.863 . Steroid compounds inhibit the growth of fungi, either through the cytoplasm or interfere with the growth and development of fungal spores. Steroids may act as antifungals because the lipophilic properties possessed by steroids can inhibit the spore germination of fungi [10].
The SEM test was performed to see the morphological changes of fungal cells both before and after contact with the extract/fraction. Morphological changes that occur in C. albicans and M. gypseum cells are suspected due to secondary metabolite activity contained in the extracts and fungus fungi. The formation of small protrusions on microbial cells due to the inability of peptidoglycan cells damaged by antimicrobial compounds that withstand high intracellular pressure, so the cytoplasm exits and this bulge usually appears in regions attenuated by compounds antimicrobials [1].

\section{CONCLUSION}

The results showed that extract and fracture of A. auricula had antifungal activity against the test fungi with the best KHM and KFM value on the ethyl acetate fraction on C. albicans at concentration of 512 $\mu \mathrm{g} / \mathrm{mL}$, equivalence between ethyl acetate fraction of the ear mushroom 
to nystatin was $0.1 \mathrm{mg} / \mathrm{mL}$ and ethyl acetate fungus fraction equivalent to $0.01116 \mathrm{mg} / \mathrm{mL}$ nystatin, SEM showed morphological changes in the test fungus after the extract and fracture of the ear mushroom were compared with the control.

\section{ACKNOWLEDGMENT}

The author thanks to Bandung School of Pharmacy for providing financial assistance and P3M STFB.

\section{REFERENCES}

1. Yani M, Sukandar Y, Adnyana E, Ketut I. Study of anti-bacterial activity of ethanol extract and singayan fungal fraction (Petiveria alliacea) against resistant bacteria. Pharm Mag Indones 2011;22:293-9.

2. Illnait-Zaragozi MT, Martinez RE, Ferrar JI, Audreu CM, Machin GF, Lancha MR, et al. In vitro antifugal activity of crude hydro-alcoholic extract of Petiveria alliacea $\mathrm{L}$ on clinical candidia isolates. Clin Microbial 2014;3:159.

3. Kemenkes RI. Riskerdasnas 2010. Jakarta: Center for Health Development Research; 2011.

4. Misaki A, Kakuta M, Sasaki T, Tanaka M, Miyaji H. Studies on interrelation of structure and antitumor effects of polysaccharides: antitumor action of periodate-modified, branched $(1 \rightarrow 3)-\beta$-D-glucan of Auricularia auricula-judae, and other polysaccharides containing $(1 \rightarrow 3)$-glycosidic linkages. Carbohydr Res 1981;92:115-29.

5. Eijikeme N, Uzoeto HO. Antimicrobial activity of some local mushrooms on pathogenic isolates. Int J Curr Res 2011;3:1-5.

6. Indriyanti N, Adnyana IK, Sukandar EY. Activity of ethanol extract and root fruit of singawalang (Petiveria alliacea $\mathrm{L}$.) against mushroom causes of dandruff with broth microdilution method. J Trop Pharm Chem 2013;2:113-7.

7. CLSI. M38-A2 Reference Method for Broth Dilution Antifungal Susceptibility Testing of Filamentous Fungi. Approved Standard. $2^{\text {nd }}$ ed. Wayne, Pennsylvania: Clinical and Laboratory Standard Institute; 2008. p. 89-96

8. Akhyar R. Power Test Barrier and TLC Analysis Bioautography Extract Roots and Mangroves (Rhizophora stylosa Griff.) Against Vibrio Harveyi. Thesis Pharmacy Program Faculty of Pharmacy Hasanuddin University; 2010. p. 35-8.

9. Rostinawati T. Antimicrobial Activity of Tespong Herba Extract (Oenanthe javavica D.C) Against Eschericia coli, Staphylococcus aureus and Candida albicans. Jatinangor: Mandiri Research; 2010. p. 23-6.

10. Alfiah RR, Rieska R, Khotimah S, Turnip M. Effectiveness of metanol extract of rilled leaves (Mikania micrantha Kunth) against Candida albicans mushroom growth. Protobiont Biol Study 2015;5:1. 